University of Nebraska - Lincoln

DigitalCommons@University of Nebraska - Lincoln

USDA Wildlife Services - Staff Publications

U.S. Department of Agriculture: Animal and Plant Health Inspection Service

2018

Fertility control for managing free-roaming feral cattle in Hong

Kong

Giovanna Massei

National Wildlife Management Centre, gmassei@botstiber.org

Ka-Kei Koon

Hong Kong Special Administrative Region, cathy_kk_koon@afcd.gov.hk

Siu-lun Law

Hong Kong Special Administrative Region, lucia_sl_law@afcd.gov.hk

Matt Gomm

National Wildlife Management Centre, Matthew.Gomm@apha.gsi.gov.uk

Darcy S. O. Mora

USDA APHIS Wildlife Services, Darcy.Mora@aphis.usda.gov

See next page for additional authors

Follow this and additional works at: https://digitalcommons.unl.edu/icwdm_usdanwrc

Part of the Life Sciences Commons

Massei, Giovanna; Koon, Ka-Kei; Law, Siu-lun; Gomm, Matt; Mora, Darcy S. O.; Callaby, Rebecca; Palphramand, Kate; and Eckery, Douglas C., "Fertility control for managing free-roaming feral cattle in Hong Kong" (2018). USDA Wildlife Services - Staff Publications. 2196.

https://digitalcommons.unl.edu/icwdm_usdanwrc/2196

This Article is brought to you for free and open access by the U.S. Department of Agriculture: Animal and Plant Health Inspection Service at DigitalCommons@University of Nebraska - Lincoln. It has been accepted for inclusion in USDA Wildlife Services - Staff Publications by an authorized administrator of DigitalCommons@University of Nebraska - Lincoln. 


\section{Authors}

Giovanna Massei, Ka-Kei Koon, Siu-lun Law, Matt Gomm, Darcy S. O. Mora, Rebecca Callaby, Kate Palphramand, and Douglas C. Eckery 


\title{
Fertility control for managing free-roaming feral cattle in Hong Kong
}

\author{
Giovanna Massei ${ }^{\mathrm{a}, *}$, Ka-Kei Koon $^{\mathrm{b}}$, Siu-Iun Law ${ }^{\mathrm{b}}$, Matt Gomm ${ }^{\mathrm{a}}$, Darcy S.O. Mora ${ }^{\mathrm{c}}$, \\ Rebecca Callaby ${ }^{\mathrm{a}}$, Kate Palphramand ${ }^{\mathrm{a}}$, Douglas C. Eckery ${ }^{\mathrm{c}}$ \\ ${ }^{a}$ National Wildlife Management Centre, Animal and Plant Health Agency, York, UK \\ ${ }^{\mathrm{b}}$ Agriculture, Fisheries and Conservation Department, Animal Management (Operation) Division, Hong Kong Special Administrative Region \\ ' USDA APHIS National Wildlife Research Center, Fort Collins, CO, USA
}

\section{A R T I C L E I N F O}

\section{Article history:}

Received 17 May 2018

Received in revised form 26 September

2018

Accepted 29 September 2018

Available online 22 October 2018

\section{Keywords:}

Bos taurus

Bos indicus

Contraception

Feral livestock

GnRH vaccine

\begin{abstract}
A B S T R A C T
Human-wildlife conflicts are increasing worldwide. For instance, growing numbers of free-roaming feral cattle in Hong Kong are causing traffic accidents and damaging crops. Public antipathy towards lethal methods to manage wildlife has promoted research into alternative options, such as fertility control. The aims of this study were to assess the potential side effects and effectiveness of the injectable immunocontraceptive vaccine GonaCon on free-roaming feral cattle in Hong Kong. Sixty female cattle were captured and randomly assigned to treatment or control groups. Treatment animals were administered one dose of GonaCon, followed by a booster dose 3-6 months later. Control animals were administered an equivalent dose of a saline solution. The side effects of GonaCon were assessed by monitoring injection site, body condition and body weight at vaccination, at the booster stage and one year after initial vaccination. At the same times, blood samples were collected to quantify antibodies to the vaccine and to assess pregnancy status. GonaCon did not affect the body weight or body condition of cattle and had no adverse side effects such as injection site reactions, limping or abnormal behaviour. GonaCon did not appear to interrupt ongoing pregnancies but reduced fertility significantly: the proportion of pregnant animals in the GonaCon-treated group decreased from $76 \%$ at initial vaccination to $6 \%$ one year after vaccination, compared to $67 \%$ and $57 \%$ respectively in the control group. There was no difference between antibody titres at the booster stage or one year post vaccination, suggesting the booster dose maintained antibody levels. This study confirmed that GonaCon is safe and effective in inducing infertility in feral cattle, with a booster dose critical for maintaining infertility.
\end{abstract}

Crown Copyright $\odot 2018$ Published by Elsevier Ltd. All rights reserved.

\section{Introduction}

Human-wildlife conflicts, often associated with overabundant animal populations, are increasing worldwide [36,17,12,24]. In parallel, public antipathy to culling, traditionally used to mitigate these conflicts, has grown because of concerns about animal welfare, human safety in urban settings and environmental impact of some culling methods $[3,38,8]$. This has promoted interest in alternative options, such as fertility control, to manage overabundant animal populations $[10,11,16,6]$. In particular, single-dose, injectable immunocontraceptive vaccines are increasingly advocated as alternative or complementary to culling for controlling wildlife populations $[21,9,25]$. These vaccines act by inducing anti-

\footnotetext{
* Corresponding author.

E-mail addresses: Giovanna.Massei@apha.gsi.gov.uk(G. Massei), cathy_kk_koon@ afcd.gov.hk (K.-K. Koon), lucia_sl_law@afcd.gov.hk (S.-I. Law), Matthew.Gomm@ apha.gsi.gov.uk (M. Gomm), Darcy.Mora@aphis.usda.gov (D.S.O. Mora), Rebecca. Callaby@apha.gsi.gov.uk (R. Callaby), kate.palphramand@apha.gsi.gov.uk (K. Palphramand), Douglas.C.Eckery@aphis.usda.gov (D.C. Eckery).
}

bodies to proteins or hormones essential for reproduction. One of these contraceptives, an injectable, single-dose gonadotropinreleasing hormone $(\mathrm{GnRH})$ vaccine, GonaCon, significantly decreased fertility for one to six years in white-tailed deer, Odocoileus virginianus, wild boar and feral pigs, Sus scrofa, cats, Felis catus, horses, Equus caballus, and bison, Bison bison $[31,19,27,26])$. GonaCon induces an immune response to the GnRH, which in turn affects the cascade of reproductive hormones that lead to ovulation [31]: following vaccination with GonaCon, females do not exhibit oestrous [20]. In most species, the contraceptive effect of the vaccine decreases with time $[30,26,35]$ although infertility can be maintained for multiple years [18,14,23,39,29,22].

The side effects associated with the use of GonaCon in some species include granulomatous nodules and sterile abscesses at injection sites and in lymph nodes (white-tailed deer, Odocoileus virginianus; [15]; elk, Cervus elaphus; [34] although no evidence of limping or impaired mobility has been reported. Conversely, no adverse effects were found in GonaCon-treated wild boar [27,26], prairie dogs, Cynomys ludovicianus [39] or wild horses [16]. 
In Hong Kong, feral cattle, Bos Taurus and Bos indicus, were traditionally used as draught animals. In the $1950 \mathrm{~s}$, due to a decline in agricultural activities, cattle were released into the wild by local farmers. At present, most free-roaming feral cattle are located away from the highly urbanised areas of Hong Kong in four main areas: Lantau Island, Sai Kung/ Ma On Shan, Central New Territories and Northeast New Territories (Fig. 1). The impacts of feral cattle include traffic disturbance and accidents, environmental nuisance and crop damage. However, these animals are valued as local heritage and some Hong Kong stakeholders support nonlethal control to manage this species [1]. In 2011, the Agriculture Fisheries and Conservation Department (AFCD) set up a Cattle Management Team for the long-term management of feral cattle, which in 2013 were estimated to be circa 1100 individuals [1]. One of the options the AFCD explored is surgical sterilisation: feral cattle are captured and transported to the Cattle Team Operation Center, surgically sterilised, and either returned to their natal area or relocated to country parks. As capture and transport of cattle are impossible in remote areas, immunocontraception was evaluated in 2013 in captive trials as an alternative to surgical sterilisation [28]. The captive study concluded that GonaCon was safe and effective in reducing fertility in cattle as 8 of the 12 cows treated with a single dose of GonaCon became infertile and all 10 control cattle became pregnant. Cattle that had been surgically sterilized through removal of the oviducts (thus still cycling) and administered a booster dose had higher anti-GnRH antibody titres than cattle that received a single dose [28]. The study concluded that a booster dose was likely to be more effective in maintaining infertility and suggested to test this hypothesis on free-roaming, nonsurgically sterilised cattle.
Building on these results, the aims of the present study were: 1) to evaluate the effect of a primer and a booster dose of GonaCon on the health and on the reproductive output of feral cattle; 2) to assess the safety of GonaCon in animals that were pregnant when vaccinated and; 3 ) to examine factors potentially affecting the immune response of feral cattle vaccinated with GonaCon.

\section{Methods}

Due to the difficulty of recording body weights of cattle in the field, a trial with captive cattle was carried out to assess the accuracy of body weight estimated by trained staff. The body weights of 19 cattle housed at the Operation Center were regressed against independent estimates provided by three members of the Cattle Team. The equation obtained from the regression of the mean estimated body weight (EstBW) versus the actual body weight (BW) of captive animals was BW $=$ EstBW $* 0.948+19.489$ (Fig. 2). This equation was used to calculate the body weight of feral cattle (range: $150-420 \mathrm{~kg}$ for animals $\geq 1$ year old).

Between June and August 2015, sixty feral female cattle from 13 locations (Fig. 1) were caught. A Power Analysis was carried out to calculate the sample size required for treated and control animals. This analysis was based on the expectation that at least $70 \%$ of the cattle sampled would be pregnant (Cattle Team observations, unpublished) and that two doses of GonaCon would render infertile at least $75 \%$ of the animals. Based on the Power Analysis, the sixty cattle were randomly assigned to Treatment ( $T: n=42$ ) or Control ( $\mathrm{C}: \mathrm{n}=18$ ) groups. A dart gun $\left(\mathrm{CO}_{2}\right.$ injection rifle, DANINJECT ApS, Denmark) was used to administer a combination of $0.003 \mathrm{mg} / \mathrm{kg}$ etorphine/acepromazine (Immobilon, Novartis

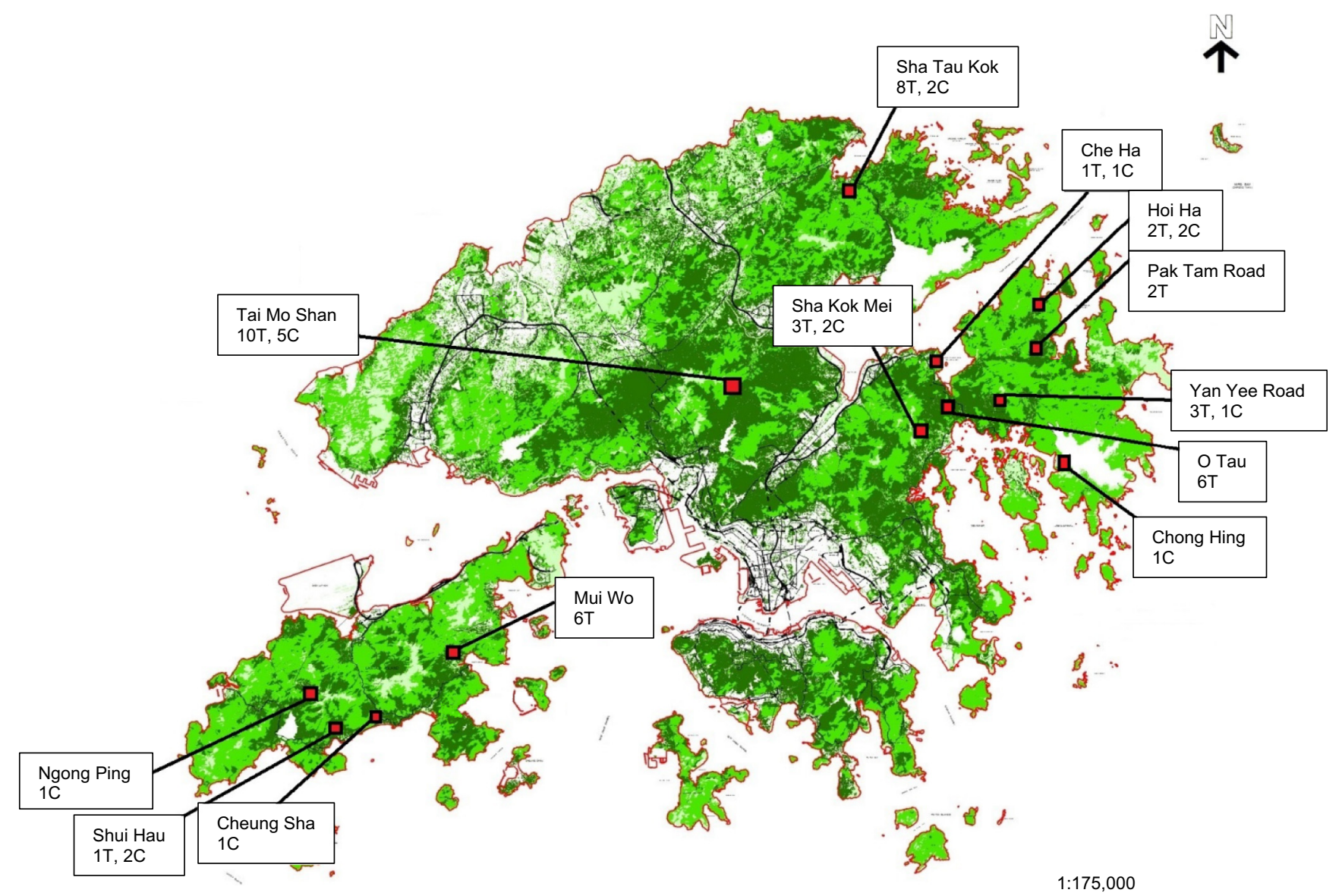

Fig. 1. Distribution of the cattle herds (filled squares) in Hong Kong. $T=$ number of treated cattle; $C=$ number of control cattle. 


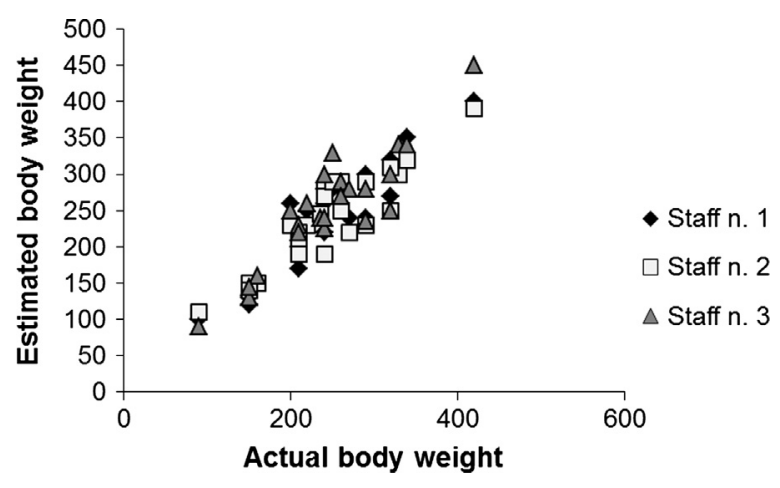

Fig. 2. Body weight (in $\mathrm{kg}$ ) of cattle $(\mathrm{n}=19)$ in captivity, estimated independently by three staff of the Cattle Team versus actual body weight.

Animal Health UK Ltd, Surrey, UK) and $0.4 \mathrm{mg} / \mathrm{kg}$ xylazine (Ilium Xylazil-100, Troy Laboratories Pty. Limited, Australia) intramuscularly. Treatment animals were given an intramuscular injection of $3 \mathrm{ml}$ of GonaCon (1000 ug/ml of GnRH-mollusk-hemocyanin conjugate; lot number: GCRD05262015; USDA, Fort Collins, CO, USA) in the neck. Control animals were injected with an equivalent volume of a $0.9 \%$ saline solution (Sodium Chloride Injection; Thai Otsuka Pharmaceutical Co. Ltd., Thailand). Each animal was marked with a numbered plastic and a metal ear tag (one tag per ear) for remote identification. The following data were collected: estimated body weight (in $\mathrm{kg}$ ), estimated age, body condition score and reproductive output. Age was assessed by tooth eruption and replacement up to 4 years old [37] or estimated by tooth wear. Body condition scores (BCS) were assigned on a scale of 1 to 5 with $1=$ poorest condition, $3=$ ideal and $5=$ overweight [5]. Animals were defined as reproductively active if observed either "lactating" (the udder appeared extended or milk could be expressed when the animal was sedated) or "with calf" (an animal was nursing a calf or being followed by one). For each cow, $24 \mathrm{ml}$ of blood was collected in three untreated Vacutainers and one EDTA-treated Vacutainer (BD Vacutainers, Plymouth, UK, $6 \mathrm{ml}$ blood per Vacutainer) for anti-GnRH antibody assays and for the pregnancy test. The sera used for anti-GnRH antibody assays were stored at $20^{\circ} \mathrm{C}$ until assayed. Once data were collected, anaesthesia was reversed using a mixture of $0.003 \mathrm{mg} / \mathrm{kg}$ diprenorphine (Revivon, Surrey, UK) and $2 \mathrm{mg} / \mathrm{kg}$ tolazoline (Lloyd Laboratories N.Z. Ltd., New Zealand) administered intravenously. Animals were observed ad-hoc once a week (by the Cattle Team and by local NonGovernment Organisations (NGO)) for up to three months following vaccination to monitor potential welfare issues.

Three to six months after initial vaccination (November 2015 to January 2016), attempts were made to relocate as many of the study animals as possible to collect blood samples (under anaes- thesia, as described previously), administer a booster dose of the vaccine and assess welfare. The T group was injected with $1 \mathrm{ml}$ of GonaCon and the $C$ group was injected with $1 \mathrm{ml}$ of saline solution. Eleven to 12 months after initial vaccination (May to July 2016), attempts were made to relocate as many of the study animals as possible to collect blood samples (under anaesthesia, as described previously) to assess anti-GnRH antibody titre and reproductive output. As animals were anaesthetised, it was not possible to carry out a rectal palpation, commonly used to detect pregnancy in this species [28]. The pregnancy status of animals in $T$ and $C$ groups at initial vaccination, at the booster stage and 11-12 months after initial vaccination was assessed using a Rapid Visual Pregnancy Test kit (IDEXX Laboratories, Inc., USA) for the detection of the pregnancy-associated glycoproteins (PAGs) in bovine serum, which are expressed from the second month of gestation until calving [13]. The limitations of this test are that: (1) PAGs can be detected 28 days post-breeding at the earliest, thus early pregnancy cannot be determined and; (2) PAGs have a halflife of 60 days, therefore a positive result may occur up to 60 days post-calving. Therefore, the pregnancy status of cattle was interpreted based on both the PAGs pregnancy test and on direct observations of births of calves in the field. The following data were collected at the booster dose stage and one year after vaccination: estimated body weight, body condition score and reproductive output (lactating, presence of a calf). Ad-hoc observations by the Cattle Team or by NGOs established the date study animals gave birth. Based on a nine month gestation [2]and on the approximate date of birth of calves, the stage of pregnancy of all cattle at initial vaccination was estimated.

The effectiveness of the vaccine to induce infertility was assessed by: (1) the immune response to the vaccine, quantified by measuring serum anti-GnRH antibodies; (2) pregnancy status and (3) presence of a calf that could be attributed to a study animal. An enzyme-linked immunosorbent assay (ELISA) was used to measure anti-GnRH antibody titres as described in Massei et al. [28]. Anti-GnRH antibody titres were expressed as the highest dilution at which the post-vaccination sample had a higher absorbance value than the mean $(+2 \mathrm{SD})$ value of the pre-vaccination samples. To eliminate potential for bias, the ELISA tests were performed by a technician blinded to the original treatment group of each serum sample.

\subsection{Statistical analyses}

Unless otherwise specified, statistical analyses were carried out comparing data collected on $\mathrm{T}$ and $\mathrm{C}$ groups at initial vaccination, booster dose and one year after vaccination (Table 1 ). In the linear mixed effects models used to evaluate the effect of GonaCon on body condition scores and on factors potentially affecting the immune response to vaccination with GonaCon, cow identity was

Table 1

Description of the statistical analyses used throughout the study.

\begin{tabular}{|c|c|}
\hline Test & Used to evaluate \\
\hline Wilcoxon-Mann-Whitney & Age differences between cattle of $\mathrm{T}$ and $\mathrm{C}$ groups \\
\hline \multirow[t]{7}{*}{ Fisher's exact } & $\begin{array}{l}\text { Effect of GonaCon on health by comparing BCSs at initial vaccination and one year after vaccination. BSCs were pooled into two } \\
\text { categories: }\end{array}$ \\
\hline & Poor condition (score 1 or 2 ), Good condition (score, 3,4 or 5 ) \\
\hline & Effect of GonaCon on reproductive output comparing: \\
\hline & 1. Cattle in $\mathrm{T}$ and $\mathrm{C}$ groups which were pregnant, lactating or with calves at each stage \\
\hline & 2. Pregnancy between younger cows ( $<1$ and $<2$ years old) and older cows ( $\geq 2$ years old) \\
\hline & $\begin{array}{l}\text { 3. The number of } \mathrm{T} \text { and } \mathrm{C} \text { cattle that were pregnant at vaccination and that had given birth (based on field observations) to assess if } \\
\text { GonaCon interrupted pregnancies }\end{array}$ \\
\hline & $\begin{array}{l}\text { 4. The association between anti-GnRH antibody titres (pooled into three categories: Low }(\leq 8) \text {, Medium }(16 \leq \mathrm{X} \leq 128) \text {, High }(>128) \text { ) } \\
\text { and infertility }\end{array}$ \\
\hline Linear mixed effects models & Effect of factors potentially affecting the immune response to vaccination with GonaCon \\
\hline Wilcoxon for paired data & Difference in the distribution of anti-GnRH antibody titres of cattle at the booster stage and one year after vaccination \\
\hline
\end{tabular}


included as a random effect to account for repeated measures. Treatment group, estimated age, stage of study and pregnancy status at each stage were included as fixed effects. Generalized linear mixed models were built using the nlme package in $\mathrm{R}$ version 3.2.4 [33]. Backwards stepwise selection based upon the Akaike information criteria (AIC) was used to choose the optimal model.

\section{Results}

Of the sixty cattle captured, one $\mathrm{T}$ animal died under anaesthesia and one $C$ cattle had to be euthanised one month after vaccination, due to a maggot-infested ear infection. No injection site reactions or any other abnormal behaviour were observed in animals in the $\mathrm{T}$ group in the months following vaccination. Three to six months after initial vaccination, $51(T: n=38, C: n=13)$ of the remaining 58 animals (88\%) were located and administered the booster dose. Approximately one year after vaccination, 49 ( $\mathrm{T}: \mathrm{n}=35, \mathrm{C}: \mathrm{n}=14$ ) of the remaining 58 animals (86\%) were located and sampled. At vaccination, there was no difference in the age of cattle in $T$ and $C$ groups $(\mathrm{w}=288.5, p=0.410)$, which ranged between 10 months and 12 years old (mean $=5.5$ years, $\mathrm{SD}=3.3 ; \mathrm{C}$ age range $=0.8-10$ years; $\mathrm{T}$ age range $=0.8-12$ years ).

At initial vaccination, cattle in the $\mathrm{T}$ group were heavier than those in the $\mathrm{C}$ group $(\mathrm{t}=2.45, \mathrm{df}=57, p<0.001)$. Body weight was affected by age $(t=2.20, d f=96, p=0.024)$; older animals were heavier than younger ones. In the $\mathrm{T}$ group, there was no difference between BCSs at vaccination and one year post vaccination $(p=0.33)$, with 41 of 42 cattle assigned to good condition at vaccination and 32 of 35 cattle assigned to good condition one year later.

At vaccination, 70\% (42 out of 60 ) of all the animals were pregnant and there was no difference in the proportion of pregnant cattle in T (76\% i.e. 32 out of 42 animals) and C groups (67\%, i.e. 12 out of 18 animals) ( $p=1.000$ ) (Fig. 3). There was no difference in the proportion of pregnant cattle in T (47\%) and C (46\%) groups at the booster stage $(p=0.749)$. One year after vaccination, the proportion of pregnant cattle in the T group (6\%) was significantly different from that in the $C$ group $(57 \%)(p<0.001)$.

There was no difference in the proportion of cattle lactating between $T$ and $C$ groups at initial vaccination $(T=21 \%, C=19 \%$; $p=1.000)$, at the booster stage ( $T=37 \%, C=25 \% ; p=0.510)$, or one year after vaccination ( $T=58 \%, C=61 \% ; p=1.000$ ). Similarly, there was no difference in the proportion of cattle with calves at initial vaccination ( $\mathrm{T}=42 \%, \mathrm{C}=25 \%$; $p=0.360$ ), at the booster stage $(\mathrm{T}=32 \%, \mathrm{C}=41 \% ; p=0.728)$, or one year after vaccination $(\mathrm{T}=50 \%$, $C=54 \% ; p=1.000)$. Young age did not affect the proportion of

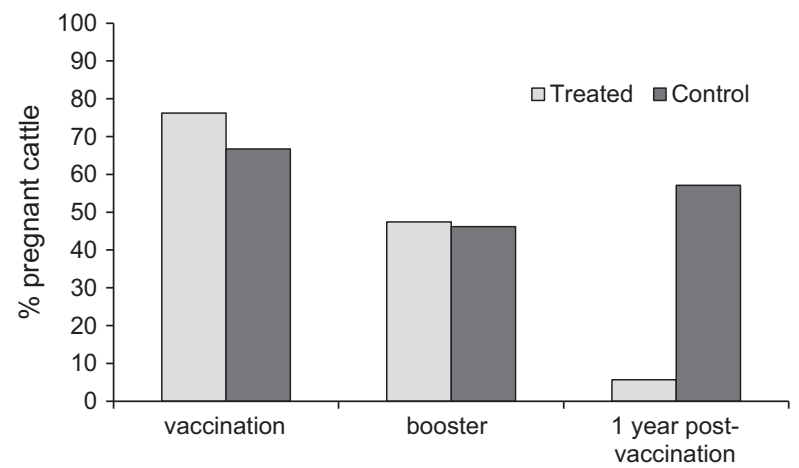

Fig. 3. Proportion of feral cattle within Hong Kong study population found to be pregnant over time; Treated cattle $(n=42)$ injected with the immunocontraceptive GonaCon, Control cattle $(\mathrm{n}=18)$ injected with a saline solution. GonaCon was injected as an initial dose (vaccination: $3 \mathrm{ml} /$ animal), followed by a booster dose (1 ml/animal) 3-6 months after vaccination with the first dose. Control animals received an equivalent volume of a saline solution.

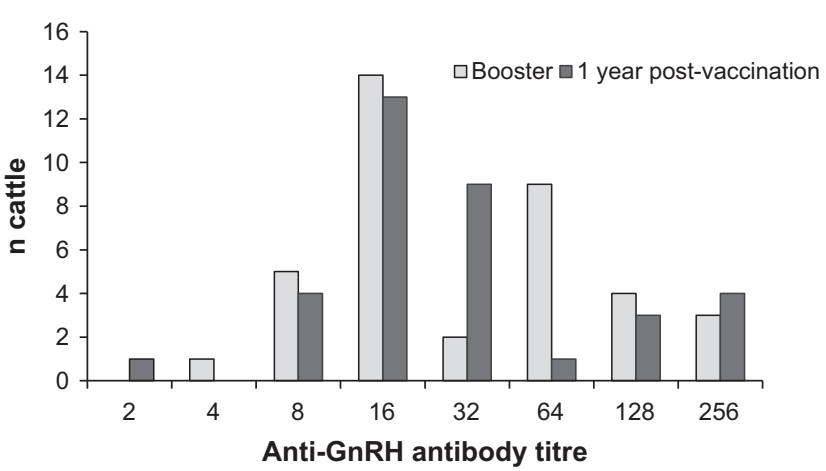

Fig. 4. Anti-GnRH antibody titre of treated cattle at booster vaccination and one year after initial vaccination. Antibody titres expressed as $\times 1000$.

Table 2

Number of cattle found pregnant or not pregnant in relation to anti-GnRH antibody titres recorded one year after animals had been vaccinated with GonaCon. Anti-GnRH antibody titres are expressed as $\times 1000$ and pooled in three categories.: low $(\leq 8)$, medium $(16 \leq \mathrm{X} \leq 128)$ and high $(>128)$.

\begin{tabular}{lll}
\hline Antibody Titre & Not Pregnant & Pregnant \\
\hline Low $(\leq 8)$ & 4 & 1 \\
Medium $(16 \leq \mathrm{X} \leq 128)$ & 22 & 1 \\
High $(>128)$ & 7 & 0 \\
\hline
\end{tabular}

cattle found to be pregnant: the proportion of pregnant $\leq 1$ year old and $<2$ year old cattle did not differ from that found in animals $\geq 2$ years of age ( $p=0.487$ and $p=1.000$ respectively).

Among the cattle that were found to be pregnant at vaccination, 29 births of calves in the T group (out of 32 cattle that were pregnant according to the blood test) and 10 births in the $C$ group (out of 12 cattle found pregnant according to the blood test) were recorded by direct observation in the year following vaccination. All 10 (100\%) C animals and 28 out of 29 T cattle delivered a calf in the year following vaccination. There was no difference $(p=1.000)$ between the proportion of $T$ and $C$ cattle that were pregnant at vaccination and that had given birth within a year. For cattle in the T group, the 28 calves for which the date of birth was available were born between 2 and 9 months after vaccination (mean: 5.1 months, SD: 1.8).

All cattle in the $\mathrm{T}$ group developed anti-GnRH antibody titres. The distribution of anti-GnRH antibody titres did not differ between booster and one year after vaccination stages $(\mathrm{v}=154.5$ $p=0.840$ ) (Fig. 4). Cattle with a high anti-GnRH antibody titre $(>128)$ one year after vaccination were less likely to become pregnant than individuals with a lower titre $(p<0.0001$, Table 2$)$.

\section{Discussion}

The results of this study showed that GonaCon was safe when administered to feral cattle as a single dose vaccination followed by a booster dose three to six months later. No side effects of GonaCon treatment, such as injection site reactions or abnormal behaviour, were observed at any stage and GonaCon did not affect body condition. These findings are consistent with previous studies, which found no general side effects or specific injection site reactions in cattle or in several other species treated with GonaCon (wild boar: [27,26]; cattle: [4,28].

Cattle in both treatment and control groups that were pregnant at initial vaccination gave birth to calves in similar proportions, showing that vaccination with GonaCon did not affect ongoing pregnancies. This also explained why there was no difference in the proportion of females lactating or with calf between groups in the 
year following vaccination. The birth dates of calves indicated that births were widespread throughout the year and that animals had been vaccinated at different stages of pregnancy. The fact that GonaCon does not appear to affect an ongoing pregnancy at any stage is particularly important for field applications as feral cattle could be treated (or administered booster doses) safely at any time of the year.

This study indicated that two doses of GonaCon significantly reduced reproduction in cattle as the percentage of pregnant females decreased from $76 \%$ to $6 \%$ one year after vaccination, against $67 \%$ to $57 \%$ recorded in the control group respectively. A similar effect of GonaCon on infertility has been reported in several species (using a primer and booster dose as in the current study), including bison [32] and elk [34]. In female bison, four of the six animals vaccinated with $1800 \mu \mathrm{g}$ of GonaCon that were pregnant at initial vaccination delivered healthy calves but they did not reproduce the following season, whilst all five control animals produced calves [32]. Similarly, all ten elk vaccinated with $1500 \mu \mathrm{g}$ of GonaCon when pregnant delivered healthy calves but became infertile in the years following vaccination [34].

In the current study, there was no significant difference between the anti-GnRH antibody titres at the booster stage or one year post vaccination, suggesting that the booster dose maintained antibody levels. As expected, cattle with the highest levels of anti-GnRH antibody titres were less likely to be pregnant than those with lower levels. Similarly, higher anti-GnRH antibody titres have been associated with greater rates of infertility in other species, including wild boar [27,26], feral horses [19] and white-tailed deer [16].

Long-term infertility for long-lived animals can only be assessed in a multi-year study. Most multi-year studies of GonaCon found that in the years following vaccination, anti-GnRH antibody titres decreased and fertility was restored in some individuals but not in others that remained infertile for many years $[19,30,14,26]$. For instance, in captive wild boar treated with a single dose of GonaCon, titres dropped significantly in the 18 months following vaccination and then remained relatively low for the following 5 years [26] with 11 out of 12 female wild boar remaining infertile for at least 5 years after vaccination.

Although the reversibility of the contraceptive effect can be considered a disadvantage when fertility control is used to manage overabundant populations of wildlife $[7,11,25]$, temporary infertility might be desirable in other species, such as elephants and feral horses $[21,9,6]$. For example, in elephants immunocontraception was used to extend the inter-calving interval and give all females the possibility of reproducing at a lower rate [9]. The latter might be applicable to the Hong Kong cattle that many stakeholders want to retain in the area.

In conclusion, this study confirmed that GonaCon is safe and effectively induces infertility in cattle. Future field studies should focus on the long-term monitoring of the study animals to assess the longevity of the contraceptive effect. Additional research should be conducted on the feasibility and sustainability of immunocontraception at the herd level. For instance, modelling could be used to determine the proportion of a herd that must be vaccinated as well as the frequency of vaccination to achieve a set reduction in herd size.

\section{Conflict of interest statement}

None.

\section{Acknowledgments}

The study was approved in the UK by the Animal and Plant Health Agency's Animal Welfare Ethical Review Body (AWERB
30/04/2015) and by the AFCD ad-hoc Ethic Review Panel set up specifically for this trial. This study was funded by the Agriculture, Fisheries and Conservation Department, Animal Management (Operation) Division, Hong Kong SAR, China. Many thanks to Esther To for advice and support for the study and to the Cattle Team for assistance with data collection.

\section{References}

[1] AFCD. Stray Cattle and Buffalo Management Plan (2013) http://www.afcd.gov. hk/ english/quarantine/cattlebuffalo.html.

[2] Andersen H, Plum M. Gestation length and birth weight in cattle and buffaloes: a review. J Dairy Sci 1965;48:1224-35.

[3] Beringer J, Hansen LP, Demand JA, Sartwell J. Efficacy of translocation to control urban deer in Missouri: costs, efficiency, and outcome. Wildl Soc Bull 2002;30:767-74

[4] D’Occhio MJ. GonaCon trial in heifers. North Sydney: Meat \& Livestock Australia Limited; 2013.

[5] Defra (2001) Condition Scoring of dairy cows. https://www.gov. uk/government/uploads/_system/uploads/attachment_data/file/69371/ pb6492-cattlescoring-diary020130.pdf.

[6] Delsink AK, Kirkpatrick J. Free-ranging African Elephant immunocontraception. Cape Town: Trident Press; 2012.

[7] Delsink AK, van Altena JJ, Grobler D, Bertschinger H, Kirkpatrick J, Slotow R. Implementing immunocontraception in free-ranging African elephants at Makalali Conservancy. J SA Vet Assoc 2007;78:25-30.

[8] Dickman AJ. Complexities of conflict: the importance of considering social factors for effectively resolving human-wildlife conflict. Anim Conserv 2010;13:458-66.

[9] Druce HC, Mackey RL, Slowtow R. How immunocontraception can contribute to elephant management in small, enclosed reserves: Munyawana population. PLoS One 2011;6:1-10.

[10] Duka T, Masters P. Confronting a tough issue: fertility control and translocation for over-abundant Koalas on Kangaroo Island, South Australia. Ecol Manage Restor 2005;6:172-218.

[11] Fagerstone KA, Miller LA, Killian GJ, Yoder CA. Review of issues concerning the use of reproductive inhibitors, with particular emphasis on resolving humanwildlife conflicts in North America. Integr Zool 2010;1:15-30.

[12] Fernando P, Leimgruber P, Prasad T, Pastorini J. Problem-elephant translocation: translocating the problem and the elephant? PLoS One 2012;7 (12):e50917. https://doi.org/10.1371/iournal.pone.0050917. PMID: 23236404.

[13] Gajewski Z, Pertajitis M, Sousa N, Beckers J, Pawliński B, Janett F. Pregnancyassociated glycoproteins as a new diagnostic tool in cattle reproduction. Schweizer Archiv für Tierheilkund 2009;151:577-82.

[14] Gionfriddo JP, Denicola AJ, Miller LA, Fagerstone KA. Efficacy of GnRH immunocontraception of wild white-tailed deer in New Jersey. Wildl Soc Bull 2011;35:142-8.

[15] Gionfriddo JP, Denicola AJ, Miller LA, Fagerstone KA. Health effects of GnRH immunocontraception of wild white-tailed deer in New Jersey. Wildl Soc Bull 2011;35:149-56.

[16] Gray ME, Thain DS, Cameron EZ, Miller LA. Multi-year fertility reduction in free-roaming feral horses with single-injection immunocontraceptive formulations. Wildl Res 2010;37:475-81.

[17] Heydon MJ. Wildlife conflict resolution: a review of problems, solutions and regulation in England. Wildl Res 2010;37:731-48.

[18] Killian G, Kreeger TJ, Rhyan J, Fagerstone K, Miller LA. Observations on the use of Gonacon in captive female elk (Cervus elaphus). J Wildl Dis 2009;45:184-8.

[19] Killian G, Thain D, Diehl NK, Rhyan J, Miller L. Four-year contraception rates of mares treated with single-injection porcine zona pellucida and $\mathrm{GnRH}$ vaccines and intrauterine devices. Wildl Res 2008;35:531-9.

[20] Killian G, Wagner D, Fagerstone K, Miller LA. Long-term efficacy and reproductive behavior associated with GonaCon use in white-tailed deer (Odocoileus virginianus). In: Timm RM, Madon MB, editors. Proc 23rd Vert Pest Conf. David p: University of California; 2008. p. 240-3.

[21] Kirkpatrick JF, Lyda RO, Frank KM. Contraceptive vaccines for wildlife: a review. Am J Reprod Immunol 2011;66:40-50.

[22] Krause SK, Kelt DA, Gionfriddo JP, Van Vuren DH. Efficacy and health effects of a wildlife immunocontraceptive vaccine on fox squirrels. J Wildl Manage 2014;78:12-23.

[23] Levy JK, Friary JA, Miller LA, Tucker SJ, Fagerstone KA. Long-term fertility control in female cats with GonaCon, a GnRH immunocontraceptive, Theriogenology 2011;76:1517-25.

[24] Lute ML, Navarrete CD, Nelson M, Gore M. Moral dimensions of humanwildlife conflict. Conserv Biol 2016;30:1200-11.

[25] Massei G, Cowan P. Fertility control to mitigate human-wildlife conflicts: a review. Wildl Res 2014:41:1-21.

[26] Massei G, Cowan DP, Coats J, Bellamy F, Quy R, Brash M, et al. Long-term effects of immunocontraception on wild boar fertility, physiology and behaviour. Wildl Res 2012;39:378-85.

[27] Massei G, Cowan DP, Coats J, Gladwell F, Lane JE, Miller LA. Effect of the GnRH vaccine GonaCon on the fertility, physiology and behaviour of wild boar. Wildl Res 2008;35:540-7. 
[28] Massei G, Koon KK, Benton S, Brown R, Gomm M, Orahood DS, et al. Immunocontraception for managing feral cattle in Hong Kong. PLoS One 2015;10(4):e0121598.

[29] Miller LA, Fagerstone KA, Eckery DC. Twenty years of immunocontraceptive research: lessons learned. J Zoo Wildl Med 2013;44:84-96.

[30] Miller LA, Gionfriddo JP, Fagerstone KA, Rhyan JC, Killian GJ. The single-shot $\mathrm{GnRH}$ immunocontraceptive vaccine (GonaCon) in white-tailed deer: comparison of several GnRH preparations. Am J Reprod Immunol 2008:60:214-23.

[31] Miller LA, Johns BE, Killian GJ. Immunocontraception of white-tailed deer with GnRH vaccine. Am J Reprod Immunol 2000;44:266-74.

[32] Miller LA, Rhyan JC, Drew M. Contraception of bison by GnRH vaccine: a possible means of decreasing transmission of brucellosis in bison. J Wildl Dis 2004;40:725-30.

[33] Pinheiro J, Bates D, DebRoy S, Sarkar D, Heisterkamp S, Van Willigen B, et al. nlme: Linear and Nonlinear Mixed Effects Models. R package version 3.1-128; 2016. http://CRAN.
[34] Powers J, Baker DL, Davis TL, Conner MM, Lothridge AH, Nett TM. Effects of gonadotropin-releasing hormone immunization on reproductive function and behavior in captive female Rocky Mountain elk (Cervus elaphus nelsoni). Biol Reprod 2011;85:1152-60.

35] Powers JG, Monello RJ, Wild MA, Spraker TR, Gionfriddo JP, Nett TM, et al. Effects of GonaCon immunocontraceptive vaccine in free-ranging female Rocky Mountain elk (Cervus elaphus nelsoni). Wildl Soc Bull 2014;38:650-6.

[36] Rutberg AT, Naugle RE. Population effects of immunocontraception in whitetailed deer (Odocoileus virginianus). Wildl Res 2008;35:494-501.

[37] Ryan D. Cattle must have sound teeth. NSW Agriculture AGfact A0.2.2, 2nd ed. Division of Agricultural Services; 1989. www.agric.nsw.gov.au.

[38] Sharp T, Saunders G. A model for assessing the relative humaneness of pest animal control methods. Canberra: Australian Government Department of Agriculture, Fisheries and Forestry; 2008.

[39] Yoder CA, Miller LA. Effect of GonaCon vaccine on black-tailed prairie dogs: Immune response and health effects. Vaccine 2010;29:233-9. 